\title{
Numerical Study of Chemical Non-equilibrium Flow in Hydrocarbon Scramjet Nozzle
}

\author{
ZHANG Xiao-yuan \\ School of Astronautics \\ Beijing University of Aeronautics and \\ Astronautics \\ Beijing 100191, China \\ zhangxiaoyuan@sa.buaa.edu.cn
}

\author{
QIN Li-zi \\ School of Astronautics \\ Beijing University of Aeronautics and \\ Astronautics \\ Beijing 100191, China
}

\author{
LIU Yu \\ School of Astronautics \\ Beijing University of Aeronautics and \\ Astronautics \\ Beijing 100191, China
}

\begin{abstract}
The non-equilibrium flow and frozen flow of hydrocarbon scramjet nozzle were numerically simulated to research the non-equilibrium effects on the nozzle performance. The numerical results show the recombination occurs during the expansion in the scramjet nozzle, which is helpful to the nozzle performance. The calculation results suggest the influence of the inlet mach and the fuel equivalence ratio to the non-equilibrium effects on nozzle performance is visible.
\end{abstract}

Keywords-scramjet nozzle; chemical non-equilibrium effects; nozzle performance

\section{INTRODUCTION}

A scramjet consists of an inlet, an isolator, a supersonic combustor and a nozzle. As a main component, the nozzle produces most of thrust, whose magnitude and direction have decisive effects on the scramjet performance. The nozzle works in the high temperature and hypersonic environment, therefore there will be significant chemical non-equilibrium effects. Different from frozen flow and chemical equilibrium flow, the relaxation time of chemical reactions and the residence time of flow are in the same order of magnitude in the chemical nonequilibrium nozzle flow. The gradual expansion in scramjet nozzle should result in recovery of a significant fraction of the thermal energy from dissociated species present at the combustor exit. Therefore, the performance simulations of nozzles for hypersonic propulsion systems should include finite-rate chemical kinetics.

Because of the complexity of the chemical non-equilibrium flow in the scramjet nozzle, there are a series of difficulties and limitations in ground experimental study, thus numerical analysis is necessary. Research on chemical non-equilibrium flow is mostly concentrated in the axisymmetric convergentdivergent nozzle. A computer model for describing quasi-onedimensional flow was used by Sangiovanni ${ }^{[1]}$ to study the role of hydrogen/air chemistry in nozzle performance for a hypersonic propulsion system. The study shows that finite-rate chemistry should not be neglected in nozzle performance simulations because beneficial chemical processes persist throughout the entire nozzle length. Thomas Link ${ }^{[2]}$ uses a finite element code to model chemical reactions considering finite-rate chemistry and vibrational relaxations. Different test cases are computed, and the results are compared with measured and numerical data. Wang Xin-yue ${ }^{[3]}$ uses the RNG $\mathrm{k}-\varepsilon$ turbulence model and the finite volume method to solve the conservative Reynolds-Averaged Navier-Stokes equations. The calculation shows the performance of the nozzle are notably advanced under the combustion in the nozzle. The nonequilibrium chemical reactions should always be considered in research of the scramjet nozzle performance.

To study the non-equilibrium nozzle flow and the effects on the nozzle performance, the chemical non-equilibrium flow in hydrocarbon scramjet nozzle is numerical simulated assuming complete combustion at the combustor exit.

\section{PHYSICAL MODEL}

A fully integrated scramjet is one that employs the entire windward surface of the forebody in the inlet compression process and the entire windward surface of the afterbody in the exhaust expansion process. Such a vehicle is depicted schematically in Fig. 1. A representative nozzle was designed for the typical hypersonic flight vehicle with a flight condition corresponding to Mach 8 at an altitude of $30 \mathrm{~km}$.

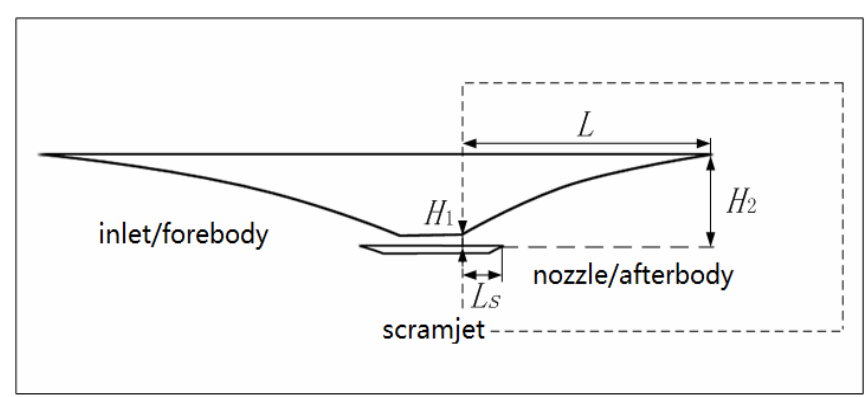

Figure 1. General Configuration of a Hypersonic Vehicle

The nozzle inlet condition is related to the flight condition and the working condition of the inlet/forebody and the combustor. According to [4] given nozzle inlet parameters, and the inlet condition used as a sample problem for this study is summarized in Table I. The mass fractions of the gas in chemical equilibrium state are calculated by the equilibrium constant method, assuming the aero-kerosene has completely combusted at the combustor exit at a fuel equivalence ratio of 1.0 . 
The nozzle is designed by the method of characteristics. The model is truncated $50 \%$ considering the nozzle gained is too long. The study ${ }^{[5]}$ shows the truncation can limit the length and weight of the nozzle without affecting the nozzle performance seriously. The geometric parameters of the nozzle are shown in Fig. $1, \mathrm{~L}=39.84 H_{1}, L_{\mathrm{s}}=9.14 \mathrm{H}_{1}, \mathrm{H}_{2}=12.76 \mathrm{H}_{1}$. The height of inlet, $H_{1}$ values $0.050 \mathrm{~m}$, and the inlet width is four times of the height.

TABLE I. NOZZLE INLET CONDITIONS

\begin{tabular}{|cl|cl|}
\hline Flight Mach & $=8.0$ & Altitude $(\mathrm{km})$ & $=30$ \\
\hline $\mathrm{T}(\mathrm{K})$ & $=2493.75$ & $\mathrm{P}(\mathrm{Pa})$ & $=118069.6$ \\
\hline $\mathrm{Ma}$ & $=2.0$ & & \\
\hline$[\mathrm{Ar}]^{\mathrm{a}}$ & $=1.205 \mathrm{E}-02$ & {$[\mathrm{H}]$} & $=6.259 \mathrm{E}-05$ \\
\hline$[\mathrm{CO}]$ & $=2.801 \mathrm{E}-02$ & {$\left[\mathrm{H}_{2}\right]$} & $=4.309 \mathrm{E}-04$ \\
\hline$\left[\mathrm{CO}_{2}\right]$ & $=1.486 \mathrm{E}-01$ & {$[\mathrm{OH}]$} & $=4.605 \mathrm{E}-03$ \\
\hline$[\mathrm{O}]$ & $=8.121 \mathrm{E}-04$ & {$\left[\mathrm{H}_{2} \mathrm{O}\right]$} & $=7.991 \mathrm{E}-02$ \\
\hline$\left[\mathrm{O}_{2}\right]$ & $=1.395 \mathrm{E}-02$ & {$\left[\mathrm{~N}_{2}\right]$} & $=7.116 \mathrm{E}-01$ \\
\hline
\end{tabular}

\section{NUMERICAL METHOD}

To simulate of viscous chemical flow inside and outside the scramjet nozzle, the conservative Reynolds-averaged NavierStokes equations are solved with the RNG k- $\varepsilon$ turbulence models and finite volume method. Ref. 6 has verified the RNG $\mathrm{k}-\varepsilon$ turbulence models used in simulating the asymmetric nozzle hypersonic flow. 8 species and 12 steps chemical reaction models ${ }^{[6]}$ shown in Table II are employed to calculate the flow.

TABLE II. REACTION MECHNISM

\begin{tabular}{llllc}
\hline NO. & \multicolumn{1}{c}{ Reaction $^{\text {b }}$} & \multicolumn{1}{c}{$A$} & $n$ & $E$ \\
\hline 1 & $\mathrm{M}+\mathrm{O}+\mathrm{O}=\mathrm{O}_{2}+\mathrm{M}$ & $2.55 \mathrm{E}+18$ & -1 & 0 \\
2 & $\mathrm{M}+\mathrm{H}+\mathrm{H}=\mathrm{H}_{2}+\mathrm{M}$ & $5.00 \mathrm{E}+18$ & 0 & 0 \\
3 & $\mathrm{M}+\mathrm{O}+\mathrm{H}=\mathrm{OH}+\mathrm{M}$ & $1.00 \mathrm{E}+16$ & 0 & 0 \\
4 & $\mathrm{M}+\mathrm{H}+\mathrm{OH}=\mathrm{H}_{2} \mathrm{O}+\mathrm{M}$ & $8.40 \mathrm{E}+21$ & -2 & 0 \\
5 & $\mathrm{CO}+\mathrm{O}+\mathrm{M}=\mathrm{CO}_{2}+\mathrm{M}$ & $6.00 \mathrm{E}+13$ & 0 & 0 \\
6 & $\mathrm{H}_{2}+\mathrm{O}_{2}=\mathrm{OH}+\mathrm{OH}$ & $1.70 \mathrm{E}+13$ & 0 & 47803.02 \\
7 & $\mathrm{OH}+\mathrm{H}_{2}=\mathrm{H}_{2} \mathrm{O}+\mathrm{H}$ & $2.19 \mathrm{E}+13$ & 0 & 51437.4 \\
8 & $\mathrm{OH}+\mathrm{OH}=\mathrm{O}+\mathrm{H}_{2} \mathrm{O}$ & $6.02 \mathrm{E}+12$ & 0 & 1092.3 \\
9 & $\mathrm{O}+\mathrm{H}_{2}=\mathrm{H}+\mathrm{OH}$ & $1.80 \mathrm{E}+10$ & 1 & 8897.28 \\
10 & $\mathrm{H}+\mathrm{O}_{2}=\mathrm{O}+\mathrm{OH}$ & $1.22 \mathrm{E}+17$ & -0.91 & 16620.8 \\
11 & $\mathrm{CO}+\mathrm{OH}=\mathrm{H}+\mathrm{CO}{ }_{2}$ & $4.00 \mathrm{E}+12$ & 1 & 8003.58 \\
12 & $\mathrm{CO}+\mathrm{O}_{2}=\mathrm{CO}{ }_{2}+\mathrm{O}$ & $3.00 \mathrm{E}+12$ & 1 & 49650 \\
\hline & b. $\mathrm{Rate}$ coefficients are in the form $\mathrm{k}=\mathrm{ATnexp}(-\mathrm{E} / \mathrm{RT})$. Units are in mole, $\mathrm{ml}$ and $\mathrm{K}$
\end{tabular}

Computational domain in rectangle shape using structured grids shows in Fig. 1. Grids are much more intensive near the wall and where the flow parameters changing heavily. The total number of computational grids is 123,520 . The nozzle inlet is given static pressure, total pressure, total temperature and gas compositions, with adiabatic no-slip boundary and far field boundary conditions.

\section{RESULT AND DISCUSSION}

\section{A. Chemical Non-equilibrium Effects on the Nozzle Performance}

The calculated results indicate the structures of the frozen flow and the non-equilibrium are almost the same. The nozzle flow is in slightly unexpanded state, because of the nozzle truncated. Fig. 2 gives the calculation results of density contour in chemical non-equilibrium flow.

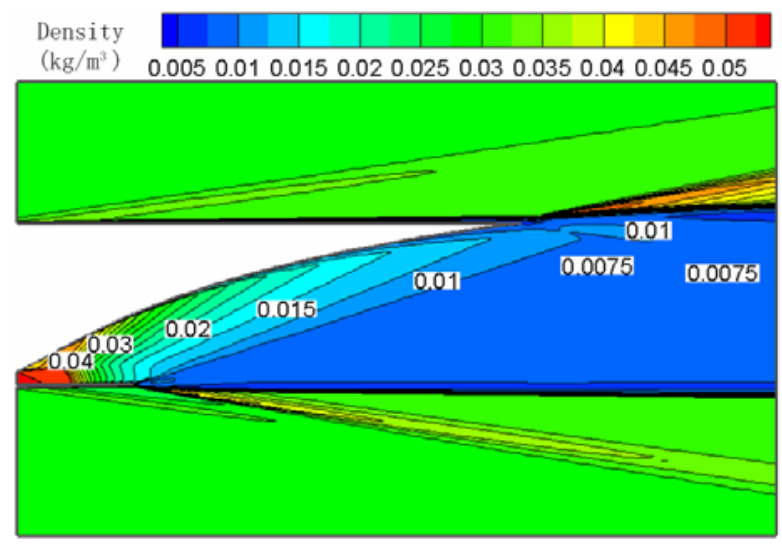

Figure 2. Density Contour

In Table III, which compares the results of thrust $\left(F_{\mathrm{x}}\right)$, lift $\left(F_{\mathrm{y}}\right)$ and pitching moment $(M)$ produced by the up-wall calculated by the frozen flow model and the non-equilibrium model. The nozzle performance calculated is nearly $4 \%$ higher in non-equilibrium model than that in frozen model due to the chemical non-equilibrium effects. As the gas at nozzle inlet is in equilibrium, the increase of the nozzle performance comes from the radical recombination during the expansion. The total temperature contour calculated in non-equilibrium model shows in Fig. 3. During expanding the gas in nozzle the total temperature increase gradually, while that has not any changing calculated in frozen model. According to the contour, the total temperature increase rapidly at the beginning of the nozzle, and it increase nearly $100 \mathrm{~K}$ during the whole process. Fig. 4 gives the transformation of the static pressure on the up-wall. The pressure in non-equilibrium model is always higher, and the difference is greater at the beginning of expansion.

TABLE III. NOZZLE PERFormance OF CONFIGURATIONS

\begin{tabular}{cccc}
\hline Case Description & $\mathrm{F}_{\mathrm{x}}(\mathrm{N})$ & $\mathrm{F}_{\mathrm{y}}(\mathrm{N})$ & $\mathrm{M}(\mathrm{Nm})$ \\
\hline Frozen & 1730.35 & 4756.56 & 3723.29 \\
Non-equilibrium & 1799.93 & 4939.47 & 3862.01 \\
Ratio of Increase & $4.02 \%$ & $3.85 \%$ & $3.73 \%$ \\
\hline
\end{tabular}




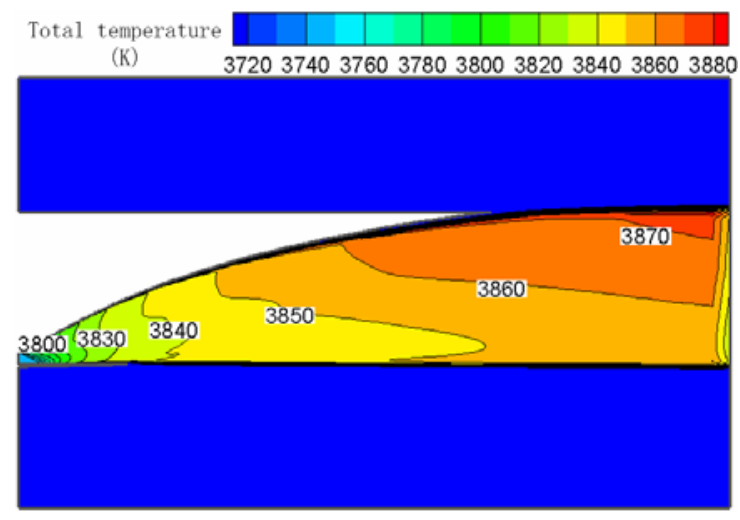

Figure 3. Total Temperature Contour

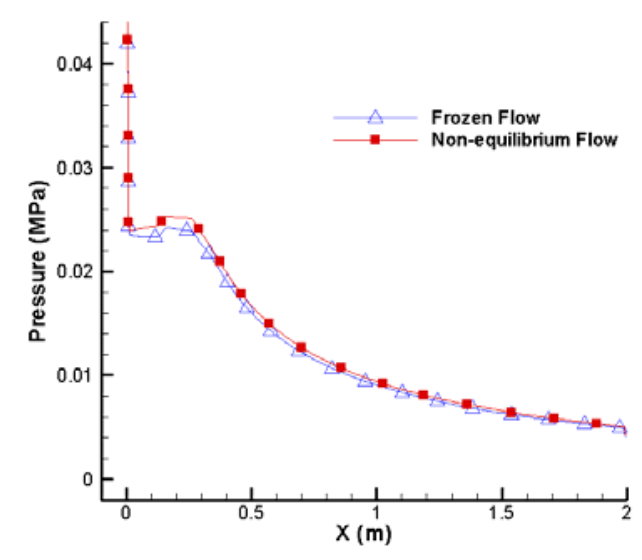

Figure 4. Transformation of Static Pressure on Up-Wall

Fig. 3, 4 and 5 show the mass fraction contours of $\mathrm{CO}, \mathrm{CO}_{2}$ and $\mathrm{H}_{2} \mathrm{O}$ calculated in the non-equilibrium flow. During the expansion, the mass fraction of $\mathrm{CO}_{2}$ increases from $14.8 \%$ at the inlet to $17.8 \%$ at the exit, meanwhile the mass fraction of $\mathrm{CO}$ decreases form $2.8 \%$ to $0.8 \%$. The visible increase of the mass fraction of $\mathrm{CO}_{2}$ and decrease of the mass fraction of $\mathrm{CO}$ indicate the recombination of $\mathrm{CO}_{2}$ during the expansion. On the other hand, the mass fraction of $\mathrm{H}_{2} \mathrm{O}$ has just a little change, a small decrease, unlike the increase of $\mathrm{CO}_{2}$. The mass fraction of $\mathrm{H}_{2} \mathrm{O}$ should increase because of the recombination, but some $\mathrm{OH}, \quad \mathrm{O}$ and $\mathrm{O}_{2}$ has been consumed because of the recombination of $\mathrm{CO}_{2}$, therefore the equilibrium has an opposite move.

The rapid change at the beginning of the nozzle indicates that most of the recombination occurs there, where the temperature is higher and the variation of parameters of flow is quicker. The temperature decreases quickly because of the rapidly expansion of the nozzle at the beginning, so the radical recombination is more obviously, while the parameters change slowly at the end of the nozzle and little recombination occurs there.

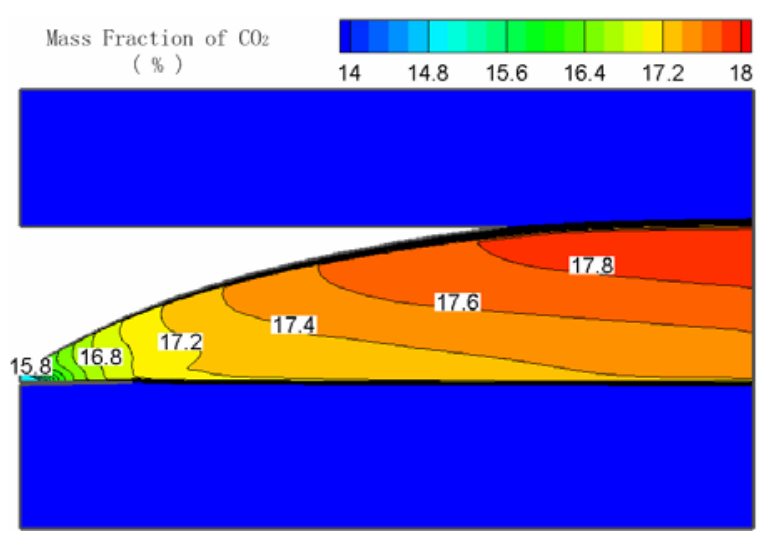

Figure 5. Mass Fraction Contour of $\mathrm{CO}_{2}$

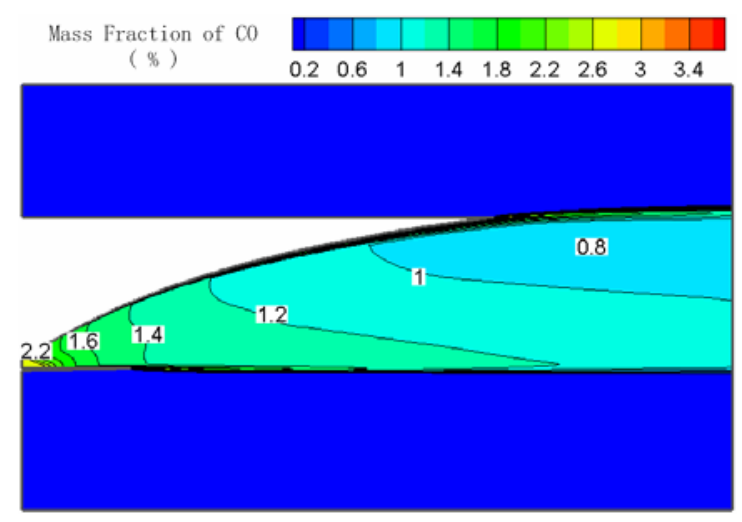

Figure 6. Mass Fraction Contour of $\mathrm{CO}$

$$
\text { Mass Fraction of } \mathrm{H}_{2} 0
$$

$(\%)$
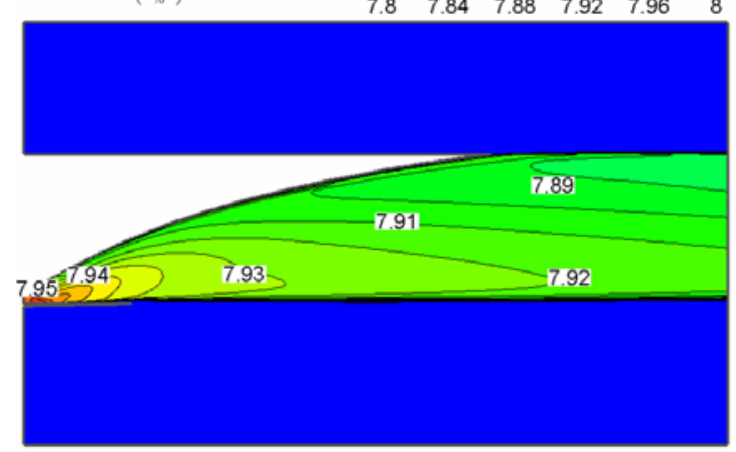

Figure 7. Mass Fraction Contour of $\mathrm{H}_{2} \mathrm{O}$

\section{B. Influence of Inlet Mach to the Chemical Non-equilibrium Effects}

Recording to the sample problem, new models are established to analysis the influence of the inlet mach to the non-equilibrium effects, varying the inlet mach and preserving the total temperature and total pressure. The physical models designed similarly and the mass fractions of the components at the inlet calculated with the same method. Compared the results of the nozzle performance calculated in frozen model and chemical non-equilibrium are given in Table IV, the difference of the nozzle performance between two models 
varies as the inlet mach. The non-equilibrium effects can be neglected when the inlet mach is 2.5 , while the push calculated is nearly $15 \%$ higher considered the chemical reaction process than in the frozen flow when the inlet mach is 1.5. As there are more dissociated components with higher temperature at the inlet, more dissociation energy releases during the process because of the higher temperature. The effects are small when the mach is 2.5 , because the less of the dissociated components.

TABlE IV. Nozzle Performance at Different Inlet Mach

\begin{tabular}{|c|c|c|c|c|}
\hline & & $\begin{array}{c}\text { Frozen } \\
\text { Flow }\end{array}$ & $\begin{array}{c}\text { Non- } \\
\text { equilibrium } \\
\text { Flow } \\
\end{array}$ & $\begin{array}{l}\text { Ratio of } \\
\text { Increase }\end{array}$ \\
\hline \multirow{3}{*}{$\begin{array}{l}\text { Inlet } \\
\text { Mac } \\
\text { h } 2.5\end{array}$} & $F x(N)$ & 680.46 & 681.80 & $0.20 \%$ \\
\hline & $F y(N)$ & 2381.59 & 2386.84 & $0.22 \%$ \\
\hline & $M(\mathrm{Nm})$ & 1285.07 & 1288.70 & $0.28 \%$ \\
\hline \multirow{3}{*}{$\begin{array}{l}\text { Inlet } \\
\text { Mac } \\
\text { h } 2.0\end{array}$} & $F x(N)$ & 1730.35 & 1799.93 & $4.02 \%$ \\
\hline & $F y(N)$ & 4756.56 & 4939.47 & $3.85 \%$ \\
\hline & $M(\mathrm{Nm})$ & 3723.29 & 3862.01 & $3.73 \%$ \\
\hline \multirow{3}{*}{$\begin{array}{l}\text { Inlet } \\
\text { Mac } \\
\text { h } 1.5\end{array}$} & $F x(N)$ & 3475.31 & 3991.84 & $14.86 \%$ \\
\hline & Fy $(N)$ & 7943.41 & 8991.94 & $13.20 \%$ \\
\hline & $M(\mathrm{Nm})$ & 8258.40 & 9196.51 & $11.36 \%$ \\
\hline
\end{tabular}

\section{Influence of Fule Equivalence Ratio to the Chemical Non-} equilibrium Effects

According to the calculated results of the up-wall push about the sample problem with varied fuel equivalence ratios from 0.6 to 1.4 shown in Table $\mathrm{V}$, the chemical nonequilibrium effects on the nozzle performance and the ratio are related. Compared the increase ratios of the push calculated in different flow models, the non-equilibrium effects are more significant when the fuel equivalence value closer to 1 . The components at the inlet vary with the fuel equivalence ratio, thus the quantity of dissociated components what would recombine during the expansion has been changed. The chemical non-equilibrium effects would be greater when the equivalence ratio closer to 1 with more recombination.
TABlE V. NOZZle Push PERFormance COMPARED

\begin{tabular}{cccc}
\hline $\begin{array}{c}\text { Equivalence } \\
\text { Ratio }\end{array}$ & $\begin{array}{c}\boldsymbol{F} \boldsymbol{x}(\boldsymbol{N}) \\
\text { in Frozen } \\
\text { Flow }\end{array}$ & $\begin{array}{c}\boldsymbol{F x}(\boldsymbol{N}) \\
\text { in Non-equilibrium } \\
\text { Flow }\end{array}$ & $\begin{array}{c}\text { Ratio of } \\
\text { Increase }\end{array}$ \\
\hline 0.6 & 1707.43 & 1752.33 & $2.63 \%$ \\
0.8 & 1721.39 & 1777.13 & $3.24 \%$ \\
1.0 & 1730.35 & 1799.93 & $4.02 \%$ \\
1.2 & 1692.78 & 1747.47 & $3.23 \%$ \\
1.4 & 1714.48 & 1755.91 & $2.42 \%$ \\
\hline
\end{tabular}

\section{SUMMARY}

The chemical non-equilibrium has obviously effects on the nozzle performance, because of the radical recombination during the expansion in the hydrocarbon scramjet nozzle. The performance calculated about chemical non-equilibrium is $4 \%$ greater than that in frozen model.

The main component in radical recombination is $\mathrm{CO}_{2}$ and the mass fraction of $\mathrm{CO}_{2}$ has a visible increase during the expansion, while the recombination of $\mathrm{H}_{2} \mathrm{O}$ is tiny.

The chemical non-equilibrium effects relate to the inlet mach and the fuel equivalence ratio. The effects are more obvious when the inlet mach decrease, and the effect would be greater when the equivalence ratio closer to 1 .

\section{REFERENCES}

[1] J. J. Sangiovanni, T. J. Barber, and S. A. Syed, "Role of Hydrogen/Air Chemistry in Nozzle Per- formance for a Hypersonic Propulsion System," Journal of Propulsion and Power, Vol. 9, No.1, 1993.

[2] Thomas Link, and W. K. Wolfgang, "Computation of a nonequilibrium expansion flow in a single expansion ramp nozzle," Journal of Propulsion and Power, Vol. 17, No. 6, 2001.

[3] Wang Xin-yue, Yang Zhen-Peng, and Wang Yan-qing, "Effects of nonequilibrium chemical reaction flow on the performance of scramjet nozzle," Journal of Aerospace Power, Vol. 24, No.5, 2009.

[4] Tohru Mitani, Shuichi Ueda, Koichiro Tani, Shigeru Sato, Hiroshi Miyajima, Masashi Matsumoto, and Shouhachi Yasu, "Validation studies of scramjet nozzle performance," Journal of Propulsion and Power, Vol. 9, No. 5, 1993.

[5] Goeing M. "Nozzle design optimization by method-of-characteristics," AIAA 1990-2024.

[6] Levin, Vladimir A. "Ignition and supersonic Burning of Air - Fuel mixtures initialted by electrical descharges," Final rept., 2006. 